\title{
Normas do Teste de Inteligência Não Verbal R-1 para Adultos Não Alfabetizados
}

\author{
Maria Olinda Gottsfritz \\ Universidade Presbiteriana Mackenzie \\ Irai Cristina Boccato Alves \\ Instituto de Psicologia da Universidade de São Paulo
}

\begin{abstract}
RESUMO
O R-1: Teste de Inteligência Não Verbal é um teste de fator $g$ brasileiro, que foi criado para ser utilizado na avaliação de motoristas, candidatos à Carteira Nacional de Habilitação (CNH). O manual mais recente deste teste não traz tabelas para uso com analfabetos. $\mathrm{O}$ objetivo deste estudo foi estabelecer normas do Teste R-1 para adultos não alfabetizados e apresentar uma análise das frequências de acertos para cada item. A amostra foi composta por 151 adultos de 16 a 77 anos, de ambos os sexos, frequentando cursos de alfabetização na cidade de São Paulo. O Teste R-1 foi aplicado coletivamente sem limite de tempo. Os resultados indicaram que as médias dos adultos analfabetos foram mais baixas do que as das pessoas com maior escolaridade, confirmando que a escolaridade exerce uma influência nas pontuações dos testes de inteligência, conforme é apontado pela literatura. A comparação da porcentagem de acertos de cada item nesta amostra com as de pessoas com maior escolaridade indicou que os itens apresentaram a mesma dificuldade relativa, com porcentagens de acerto mais baixas.
\end{abstract}

Palavras-chave: Teste R-1; analfabetismo; desenvolvimento intelectual; testes de inteligência.

\section{ABSTRACT \\ R-1 Non-Verbal Intelligence Test Norms for Illiterate Adults}

The R-1: Non-Verbal Intelligence Test is a Brazilian test to measure general intelligence. It was created to assess future drivers. However, the last published test manual does not have standards for illiterate adults. This study was designed to establish norms in the R-1 Test among illiterate adults and to present an analysis of frequencies of success for each item. The sample was composed by 151 adults, aged from 16 to 77 years of both sexes, enrolled in literacy courses in São Paulo city. The R-1 Test was collectively administered, with no time limits. Results indicated that illiterate adult's means were lower than more educated people, confirming that education influences intelligence test scores, as it was suggested by literature. A comparison of the relative frequencies of passing individual items, between the illiterate group and the more educated sample, revealed that items presented the same relative difficulty to both, although success percentages were lower for the illiterate group.

Keywords: R-1 Test; illiteracy; intellectual development; intelligence tests.

Ao se discutir o que é inteligência é necessário ter clareza do quanto esse assunto é polêmico, com várias definições elaboradas por diversos autores e sem que haja um consenso sobre este conceito. Por outro lado, discute-se o desenvolvimento da inteligência da criança e a inteligência do adulto, suas diferenças relacionadas à escolaridade, ao sexo, à origem socioeconômica e à região geográfica. Os testes de inteligência, suas contribuições e as críticas ao seu uso também são polêmicos.
Oliveira (2004) aponta que há pouco conhecimento disponível sobre a psicologia do adulto, sobretudo quanto ao funcionamento cognitivo. $\mathrm{O}$ adulto é considerado como tendo completado os estágios do desenvolvimento, principalmente a maturação biológica, mas isto não implica que as transformações pessoais, sociais e mesmo biológicas não continuem ocorrendo. Este desconhecimento é ainda maior ao se considerar os adultos não alfabetizados, sujeitos deste estudo, cujo potencial e limitações vai se procurar entender. 
Segundo a Organização das Nações Unidas (Rádio das Nações Unidas, 2004), quatro bilhões de pessoas não sabem ler e escrever, o que corresponde a $20 \%$ da população mundial, ou seja, 875 milhões ainda são analfabetos, dos quais dois terços são mulheres, isto é, mais de 580 milhões. Pinto, Sampaio e Brant (2003) comentam que cerca de $16 \%$ da população brasileira não é alfabetizada, o que representa 24 milhões de brasileiros. Entre as décadas de 80 e 90 esta porcentagem caiu de $25,1 \%$ para $16,7 \%$. O "mapa do analfabetismo no Brasil" um estudo produzido pelo Instituto Nacional de Estudos e Pesquisas Educacionais Anísio Teixeira (Pinto, Sampaio \& Brant, 2003), mostra que em apenas 19 cidades brasileiras a população possui um nível de instrução correspondente a oito séries do ensino fundamental. As diferenças regionais ficam evidentes quando se leva em conta o grau de instrução da população. Todos os dez municípios com melhores indicadores estão nas regiões sul e sudeste e as dez cidades com o menor número médio de séries concluídas estão nas regiões norte e nordeste. Por outro lado, se há mais mulheres analfabetas nas faixas etárias mais altas, há indicadores de que na faixa entre $15 \mathrm{e}$ 19 anos há o dobro de rapazes analfabetos em relação às moças e há dados semelhantes nos países de língua inglesa e na França (Carvalho, 2003). São dados inquietantes para se tentar compreender melhor o fracasso escolar, pois muitos analfabetos passaram pelos bancos escolares e desistiram, contudo este fenômeno está longe de ser compreendido em toda sua extensão.

Um outro aspecto que deve ser abordado a respeito das diferenças entre adultos alfabetizados e analfabetos vem de estudos realizados na área da neuropsicologia. De acordo com Castro-Caldas e cols. (1998, p. 1060), "aprender a ler e a escrever na infância influencia a organização funcional do cérebro humano do adulto". A aprendizagem da leitura e da escrita acrescenta uma dimensão visográfica na representação interna do sistema de linguagem. As pesquisas têm mostrado que a linguagem oral é semelhante entre alfabetizados e analfabetos, mas ocorrem diferenças entre eles no processamento fonológico, o que indica que certos aspectos ligados à capacidade de lidar com as unidades fonéticas da fala não são adquiridas espontaneamente, mas são resultantes da aprendizagem da leitura.

Petersson e cols. (2007) encontraram diferenças na especialização funcional do cérebro entre sujeitos alfabetizados e não alfabetizados. Os não alfabetizados apresentaram uma lateralização direita mais consistente, enquanto ambos os grupos mostraram diferença no córtex superior temporal. Num outro estudo, utilizando ressonância magnética, CastroCaldas e cols. (1999) encontraram diferença no tamanho do corpo caloso entre os dois grupos, indicando uma possível influência da aprendizagem da leitura no desenvolvimento biológico do cérebro.

Numa revisão da literatura sobre as diferenças intelectuais entre homens e mulheres, Flores-Mendoza (2000) encontrou estudos que mostram diferenças nas habilidades cognitivas segundo o sexo, mas não em relação à inteligência geral. Segundo a autora os estudos iniciados no começo do século XX, até agora mostram que os homens têm mais facilidade nas habilidades viso-espaciais, raciocínio matemático e mecânico; as mulheres em habilidades verbais, velocidade perceptual e memória a curto prazo. Quanto ao fator $g$ não foram encontradas diferenças significativas entre os sexos.

É claro que o método adotado pelo pesquisador interfere no tipo de resultado que este obtém. Se for feita uma investigação cultural de uma sociedade ou de uma comunidade, chega-se a conclusões que dizem respeito à cultura e à interação do indivíduo com a mesma. Se a pesquisa é sobre a família, os resultados indicarão como esses fatores afetam o desenvolvimento da pessoa e, se a investigação quer entender o raciocínio usado para se obter uma dada resposta a um teste, as conclusões provavelmente serão sobre este aspecto. Portanto, quando o pesquisador verifica o desempenho de determinada população num determinado teste, ele não acredita necessariamente que esta seja a única realidade comprovável ou que seja a mais importante, mas que é necessário delimitar a pesquisa, pois não é possível dar conta de todas as variáveis que podem interferir numa dada realidade. Assim, o teste de inteligência é apenas um instrumento que ajuda a compreender a inteligência sob uma determinada ótica, num determinado contexto de uma dada população e as diferenças que eles demonstram em relação a outras populações. Todo o conhecimento produzido é uma peça de um saber que ainda está sendo construído. Este fato leva à necessidade de se dispor de normas adequadas para cada tipo dessa população nos testes de inteligência.

Contudo, Roazzi e Souza (2002) apresentam dados muito interessantes sobre a importância da familiaridade com a situação de teste, alertando que crianças não escolarizadas provavelmente terão mais dificuldades em lidar com essa situação, pois não estão habituadas com a experiência de sentarem, ficarem quietas e prestarem atenção. Outro tema ainda muito 
debatido é a importância da hereditariedade na inteligência. Estes autores citam pesquisas que associam positivamente similaridades genéticas ao QI e outras que apontam a importância do ambiente no desenvolvimento intelectual, concluindo que avaliar mais sistematicamente a influência do ambiente no desenvolvimento da inteligência envolveria pesquisas que controlassem desde a gestação e suas intercorrências, para poder obter respostas mais consistentes. No entanto, sugerem fortemente que o ambiente responde mais pela competência do indivíduo do que os aspectos hereditários.

No Brasil, Weil e Nick (1971) estiveram envolvidos num projeto de levantamento do potencial da inteligência do brasileiro, realizado na década de 50, utilizando o teste INV. Em relação à amostra de 5.563 analfabetos, concluíram que este grupo não apresentou progresso a partir dos sete anos. Angelini e cols. (1999) também constataram a influência do ambiente no desenvolvimento da inteligência, relatando que os aumentos nos escores do Teste do Raven ao longo do tempo são paralelos às melhorias na nutrição, prosperidade, higiene, aumento de altura e da capacidade atlética e que, de acordo com Bouvier (1969), atingiram, sobretudo, os níveis socioeconômicos mais baixos.

Segundo Alves (2002), a avaliação da inteligência do adulto e os testes coletivos tiveram sua origem nos testes Army Alpha e Army Beta, que foram utilizados para a seleção de soldados por ocasião da entrada dos Estados Unidos na Primeira Guerra Mundial em 1917. Desde então ocorreram esforços no sentido de se definir o que é a inteligência e como medi-la. De acordo com Castilho (1985) e Almeida (2002), a abordagem fatorial da inteligência propõe a existência de uma ou várias aptidões na estrutura da inteligência. $\mathrm{O}$ primeiro autor que propôs o uso de análise fatorial para os testes de inteligência foi Spearman, em 1904. Esse autor afirmou que a percepção e o pensamento são a base da cognição e que esta se caracteriza pelos aspectos afetivos e conativos. Estabeleceu como hipótese que se duas habilidades estão correlacionadas entre si em alguma medida, entre ambas deve haver um fator comum, fundamental para todas as funções cognitivas de um mesmo indivíduo e amplamente variável de um indivíduo para outro. Propôs dois tipos de fatores, o específico (e), que varia entre as diferentes habilidades e entre os indivíduos, e o fator $g$, que é comum a diferentes habilidades e poderia ser entendido como uma energia mental (Spearman, 1955). Segundo Almeida (2002), o fator $g$ se relaciona às três leis de construção do conhecimento: a apreensão da experiência, a edução de relações e a edução de correlatos. Deste modo, os testes de fator $g$ enfatizam os conteúdos figurativosabstratos dos itens, propondo tarefas centradas no processo de raciocínio.

Para Cronbach (1996, p. 210), “o objetivo de Spearman era o de compreender o poder intelectual separado do conhecimento do conteúdo". As analogias mostraram ser um bom recurso para a verificação deste conceito. Entre 1930 e 1980 muito se discutiu sobre o que é inteligência, mas a partir da década de 80 surgiu uma contra-revolução em que se reconheceu que a capacidade geral permeava a maioria dos desempenhos.

Segundo Angelini e cols. (1999), o fator $g$ engloba dois componentes: a capacidade edutiva e a reprodutiva. A primeira envolve a capacidade de extrair significados das situações, ter insights, perceber aspectos não óbvios, estabelecer novos constructos para lidar com problemas complexos. A capacidade reprodutiva inclui a memorização e a reprodução de materiais verbais ligados à base cultural de conhecimento. $\mathrm{O}$ teste das Matrizes de Raven não foi originalmente criado para medir o fator $g$, porém pesquisas vêm demonstrando que as Matrizes são uma das melhores medidas isoladas de $g$. É surpreendente, também, a evidência de que ao longo do tempo vem ocorrendo um aumento significativo nos resultados dos testes e que, aparentemente, estão associados à melhora das condições de vida da população. Por outro lado existem semelhanças entre as normas obtidas em culturas diferentes, assim como é quase uma regra que "em todos os países, as normas para crianças de ambientes sócio-econômicos menos privilegiados e de áreas rurais são mais baixas do que as outras" (p.17).

$\mathrm{O}$ rendimento acadêmico está mais relacionado à capacidade reprodutiva de recordar informações, portanto talvez o sistema educacional promova os mais inteligentes para memorizar do que os mais capazes para fazerem julgamento crítico, questionarem e encontrarem soluções de problemas. Esta capacidade inclui o uso dos aspectos emocionais, sua percepção e a energia mental para lidar com eles, o que implica também em motivação.

Angelini e cols. (1999) comentam que os dados de pesquisa mais antigos indicavam que a capacidade edutiva diminuía com a idade, mas os estudos mais recentes mostram que a capacidade edutiva aumenta durante toda a vida. Segundo Alves (2002), a hereditariedade e o ambiente influem na inteligência e uma das variáveis ambientais que mais interferem na inteligência é a escolarização, o que pode ser confirmado pelo trabalho de Ceci e Williams (1997), que verifica- 
ram uma alta correlação entre o tempo de escolarização e os resultados nos testes de inteligência. "A escolarização pode ser considerada, tanto uma variável dependente, como uma variável independente em relação à inteligência" (Alves, 2002, p. 20). Alves conclui que "o resultado de um teste de inteligência deve levar em conta o grau de escolaridade da pessoa testada" (p. 21).

A partir dos dados da literatura percebe-se que a inteligência pode ser compreendida de diversas formas e os testes constituem tentativas de compreender seu funcionamento. Assim este estudo pretende conhecer o desempenho em testes de inteligência de adultos não alfabetizados e que fazem parte das camadas sociais mais desfavorecidas.

\section{O TESTE R-1}

O R-1 é um teste de inteligência não verbal, baseado na Teoria Bifatorial de Spearman, sendo considerado um teste do fator $g$. Foi desenvolvido por Rynaldo de Oliveira, em 1973, para a avaliação de sujeitos com baixa escolaridade, analfabetos e estrangeiros e para ser empregado na avaliação de motoristas. Em 2002, Alves publicou um novo manual deste teste com normas revistas e novas pesquisas de validade e precisão. Foram estabelecidas normas para seis estados do Brasil: São Paulo, Paraná, Rio de Janeiro, Espírito Santo, Pernambuco e Rio Grande do Norte. Os resultados são apresentados para os diversos graus de escolaridade e por sexo.

O teste R-1 é um teste não verbal, composto de 40 itens. Os itens são apresentados da mesma forma que os das Matrizes Progressivas de Raven, constituindose de uma figura com uma parte faltando e alternativas colocadas abaixo desta figura, entre as quais está a parte que falta. Nos itens iniciais são mostrados objetos comuns, que são estímulos concretos. Eles vão ficando mais complexos, pelo uso de figuras geométricas e pela inclusão de relações de identidade e analogia, pelo acréscimo do número de elementos na matriz e de relações de soma e subtração. A partir do item 23 aparecem relações de progressão numérica. Os 40 itens são apresentados em um caderno, com folha de resposta à parte e um crivo de correção. Para os 20 primeiros itens existem seis possibilidades de respostas e depois passam a ser oito, identificadas por letras, as quais devem ser anotadas na folha de resposta.

Em pesquisa realizada em 1995, Alves, Colosio e Ruivo obtiveram uma precisão no teste-reteste de 0,677 numa amostra de 64 sujeitos, entre 18 e 48 anos e escolaridade variando entre a $5^{\mathrm{a}}$ série do $1^{\mathrm{o}}$ grau e o $2^{\circ}$ grau completo. Os sujeitos com maior escolaridade obtiveram uma precisão mais alta $(0,696)$, mostrando maior estabilidade nos resultados, provavelmente pelo maior número de respostas aleatórias dadas pelos menos escolarizados.

A precisão pelo método das metades investigada em uma amostra do Paraná, com 2102 candidatos à carteira nacional de habilitação, obtida pela correlação entre itens pares e ímpares e corrigida pela fórmula de Spearman-Brown foi de 0,80, significante ao nível de 0,001 . A validade foi verificada pela correlação com o Teste das Matrizes Progressivas de Raven - Escala Geral, sendo encontrado o coeficiente de 0,762 entre os dois testes (Alves, 2002).

Alves, Colosio e Ruivo (1992) constataram um declínio nas médias obtidas através do R-1 com o aumento da idade, mas observaram que na amostra estudada havia mais pessoas com escolaridade primária entre os sujeitos mais velhos, o que pode ter contribuído para este resultado.

Sisto, Ferreira e Matos (2006) apresentaram um estudo comparando o R-1 com o Teste Conciso de Raciocínio (TCR), que também mede o fator $g$, com o objetivo de verificar a validade do TCR. Os sujeitos foram 65 voluntários entre 18 e 48 anos que participavam de avaliação para obter a carteira de motorista. Encontraram uma correlação satisfatória entre eles, de 0,65 para o sexo masculino, 0,53 para o feminino e 0,60 para ambos os sexos, mas comentam que o TCR tem uma distribuição de pontos mais uniforme do que o R-1.

O objetivo do presente estudo foi o de obter normas do Teste R-1 para adultos não alfabetizados e apresentar uma análise das frequências de acertos e omissões nas respostas de cada item.

\section{MÉTODO}

\section{Sujeitos}

A amostra foi composta por 151 alunos, de ambos os sexos, participantes de cursos de alfabetização de adultos, oferecidos por universidades ou escolas de ensino fundamental e médio na região de Santo Amaro, zona sul de São Paulo, com idades variando de 16 a 77 anos. A Tabela 1 apresenta a distribuição de frequência por sexo e idade, bem como as médias e desvio padrão das idades. Um aluno do sexo masculino não informou a idade. 
TABELA 1

Distribuição da Frequência das Idades por Sexo

\begin{tabular}{lccc}
\hline Idade & $\mathrm{F}$ & $\mathrm{M}$ & $\mathrm{N}$ \\
\hline $16-40$ & 32 & 45 & 77 \\
$41-77$ & 56 & 17 & 73 \\
\hline Total & 88 & 62 & 150 \\
\hline Média & 46,35 & 37,00 & 42,49 \\
DP & 13,90 & 12,32 & 14,01 \\
\hline
\end{tabular}

Pode ser observado que a amostra incluiu mais mulheres $(58,5 \%)$ do que homens $(41,2 \%)$, sendo que nas faixas etárias mais altas há predomínio das mulheres e nas mais baixas, dos homens. Os participantes são adultos analfabetos em idade produtiva, o que afeta sua capacidade de crescimento profissional e gera dificuldades para o sistema absorver este tipo de mão-de-obra. As mulheres constituem a maioria na amostra, seguindo a tendência estatística mundial em que dois terços dos analfabetos são mulheres (Rádio das Nações Unidas, 2004). Houve dificuldade de se diferenciar melhor os alunos que haviam, ou não, frequentado a escola, pois seriam necessárias entrevistas individuais que não puderam ser realizadas por falta de tempo, uma vez que só houve um contato com eles nos períodos de aula.

\section{Instrumento}

O material usado por cada aluno foi composto de um caderno de aplicação e uma folha de respostas do Teste R-1, um lápis para anotação das respostas e uma cópia ampliada dos três primeiros itens para as instruções de aplicação, mostrada pela examinadora.

\section{Procedimento}

Após a aprovação da direção e da coordenação dos cursos de alfabetização de adultos para a realização da pesquisa, foram combinadas as visitas da pesquisadora e sua auxiliar às salas de aula com as professoras das turmas no horário determinado pelas mesmas. Os testes foram aplicados por duas psicólogas com treino e conhecimento da técnica. Antes da aplicação elas se apresentaram e explicaram que se tratava de uma pesquisa para conhecer melhor como os adultos em alfabetização resolvem problemas e que para isso eles fariam algumas atividades, desde que concordassem. Invariavelmente houve uma reação muda de constrangimento e muitos alunos verbalizaram que não sabiam escrever. Foi importante ser o menos formal possível e criar um clima de colaboração com as turmas.
Em seguida foi distribuída a folha de respostas e um caderno do R-1 para cada aluno e foram lidas as instruções coletivamente de acordo com o manual, mas com a utilização da cópia ampliada dos três primeiros itens nas explicações. A aplicação foi realizada sem limite de tempo. Durante a aplicação as pesquisadoras precisaram atender muitos alunos individualmente, explicando novamente as instruções e ajudando-os a compreender qual era a tarefa pedida. Algumas pessoas mais idosas solicitaram a ajuda para todos os itens. As pesquisadoras anotaram os nomes na folha de respostas, embora alguns tenham conseguido escrever os próprios nomes.

Ficou claro o quanto esta atividade foi difícil para os alunos, uma vez que solicitaram muita ajuda e esclarecimento. Ocorreram vários tipos de dificuldades: compreender a tarefa, entender onde assinalar a resposta, copiar e reconhecer as letras e seguir a sequência dos itens na folha de respostas. Foi comum pularem folhas e terem que voltar atrás. Provavelmente uma aplicação individual, em que não fosse necessário que eles mesmos preenchessem a folha de respostas, permitiria avaliar com mais fidedignidade seu real desempenho e potencial, pois é provável que tenham ocorrido muitos acertos aleatórios.

A aplicação do R-1 foi mais demorada do que o previsto, chegando, em alguns casos, a levar cerca de uma hora e meia. As aplicações foram desgastantes para as pesquisadoras que precisaram ter um envolvimento pessoal maior do que o esperado com os alunos, inclusive foi importante uma postura mais afetiva e acolhedora. Através do contato ficou claro como era importante não se sentirem desaprovados e desvalorizados frente ao seu desempenho e o quanto eram sensíveis a respeito da própria produção. Percebeu-se também o esforço envolvido na realização da tarefa e foi necessária certa insistência para iniciarem a atividade e um acolhimento do grupo.

Não houve a apresentação formal do consentimento informado porque não sabiam ler ou escrever. Este foi explicado verbalmente, dado que apesar da insistência em pedir a colaboração, foi deixado claro 
que não eram obrigados a realizar as tarefas. Nos grupos visitados ninguém se negou a cooperar, houve apenas o caso de uma senhora, com cerca de 60 anos, que realizou os testes porque a professora conversou particularmente com ela.

\section{RESULTADOS}

A Tabela 2 apresenta as estatísticas descritivas relativas aos resultados no R-1.

TABELA 2

Estatísticas Descritivas dos Resultados do R-1 por Sexo

\begin{tabular}{lccc}
\hline & Masc. & Fem. & Total \\
\hline $\mathbf{N}$ & 63 & 88 & $\mathbf{1 5 1}$ \\
Média & 14,7 & 12,5 & $\mathbf{1 3 , 4}$ \\
Mediana & 15,0 & 12,0 & $\mathbf{1 3 , 0}$ \\
Moda & 9 & 10 & $\mathbf{6}$ \\
DP & 6,5 & 5,9 & $\mathbf{6 , 2}$ \\
Mínimo & 0 & 1 & $\mathbf{0}$ \\
Máximo & $\mathbf{2 7}$ & $\mathbf{3 0}$ & $\mathbf{3 0}$ \\
\hline
\end{tabular}

Pode-se observar na Tabela 2 que os homens apresentaram média $(14,7)$ estatisticamente maior do que as mulheres $(12,5)$, sendo que o teste $t$ entre os sexos foi 2,183, que é significante a 0,031 . Estas médias são mais baixas do que as obtidas nas amostras de São Paulo (20), Rio de Janeiro (22), Espírito Santo $(22,2)$ e Paraná $(17,3)$ para escolaridade de $1^{\mathrm{a}}$ a $4^{\mathrm{a}}$ série, no entanto, é praticamente a mesma obtida no Rio Grande do Norte (14) para a mesma escolaridade, inclusive o DP é similar. Por outro lado, nesta amostra o número de sujeitos era menor em relação às outras amostras do manual. Na amostra desta pesquisa havia um número maior de mulheres mais velhas do que de homens, isto pode explicar a tendência de apresentarem um total de pontos menor.

A Tabela 3 e a Figura 1 mostram a comparação das porcentagens de acertos desta pesquisa com a amostra relativa à $1^{\text {a }}$ a $4^{\text {a }}$ séries e à amostra total de 1992 , do Manual (Alves, 1992), bem como as porcentagens de omissões para essa pesquisa e para a amostra total de 1992.

TABELA 3

Comparação das Porcentagens de Acerto e Omissões dessa Pesquisa com a Amostra de 1992, do Manual (Alves, 2002)

\begin{tabular}{cccccc}
\hline Item & \multicolumn{3}{c}{ \% de acertos } & \multicolumn{2}{c}{ Omissão } \\
\cline { 2 - 6 } & Analfabetos & $1^{\text {a }}$ a $4^{\text {a }}$ Série & Total & Analfabetos & Total \\
\hline 1 & 100 & 99,0 & 99,6 & 0 & 0 \\
2 & 88,9 & 81,6 & 84,7 & 0 & 0,4 \\
3 & 73,2 & 89,1 & 95,6 & 1,31 & 0,5 \\
4 & 41,2 & 82,6 & 91,6 & 1,31 & 1,1 \\
5 & 58,2 & 90,5 & 95,1 & 0 & 0,2 \\
6 & 64,1 & 85,2 & 93,1 & 0 & 0,4 \\
7 & 62,7 & 88,2 & 95,2 & 0 & 0,2 \\
8 & 30,1 & 51,6 & 70,2 & 0,65 & 0,6 \\
9 & 25,5 & 41,8 & 61,5 & 0,65 & 0,7 \\
10 & 20,9 & 39,8 & 47,8 & 0 & 1,4 \\
11 & 43,8 & 69,4 & 83,5 & 0,65 & 0,6 \\
12 & 56,9 & 79,3 & 89,2 & 0 & 0,7 \\
13 & 48,4 & 69,1 & 81,1 & 0,65 & 0,8 \\
14 & 43,1 & 69,1 & 83,8 & 0 & 0,9 \\
15 & 32,7 & 60,2 & 77,6 & 0 & 0,9 \\
16 & 47,1 & 70,7 & 82,4 & 0,65 & 0,9 \\
17 & 11,1 & 20,4 & 44,7 & 0,65 & 1,1 \\
18 & 22,9 & 35,2 & 56,4 & 0 & 0,9 \\
19 & 61,4 & 78,3 & 88,5 & 0,65 & 0,9
\end{tabular}




\begin{tabular}{cccccc}
20 & 6,5 & 18,4 & 36,5 & 1,31 & 2,4 \\
21 & 58,8 & 75,3 & 86,8 & 0 & 1,4 \\
22 & 43,8 & 71,4 & 85,8 & 0 & 1,3 \\
23 & 30,7 & 62,8 & 80,3 & 0,65 & 1,2 \\
24 & 26,8 & 46,1 & 64,3 & 1,96 & 3,1 \\
25 & 16,3 & 34,9 & 46,9 & 0 & 4,1 \\
26 & 11,1 & 18,1 & 35,4 & 0 & 5,1 \\
27 & 23,5 & 49,0 & 70,6 & 0,65 & 3,6 \\
28 & 13,8 & 21,4 & 44,8 & 0,65 & 4,1 \\
29 & 29,4 & 34,9 & 38,9 & 1,31 & 5,7 \\
30 & 16,3 & 42,4 & 48,3 & 1,96 & 9,8 \\
31 & 15,0 & 12,5 & 38,0 & 1,96 & 6,3 \\
32 & 15,7 & 34,9 & 60,8 & 1,31 & 7,1 \\
33 & 15,0 & 26,6 & 37,7 & 2,61 & 9,1 \\
34 & 5,9 & 11,8 & 25,1 & 4,58 & 11,3 \\
35 & 9,8 & 15,1 & 34,5 & 3,92 & 13,6 \\
36 & 9,8 & 4,6 & 5,9 & 4,58 & 15,5 \\
37 & 11,8 & 12,8 & 18,2 & 3,92 & 18,2 \\
38 & 14,4 & 12,8 & 19,1 & 4,58 & 20,5 \\
39 & 15,7 & 9,2 & 16,3 & 3,92 & 22,7 \\
40 & 30,1 & 15,5 & 13,0 & 7,19 & 23,1 \\
\hline
\end{tabular}

As respostas erradas mais frequentes, aparentemente, expressam a não compreensão do raciocínio envolvido. Os itens 14, 17, 18, 20, 21, 22, 25, 26, 27 , $29,33,34$ e 36 apresentaram respostas erradas mais frequentemente associadas à repetição da figura mais próxima ao espaço em branco, seja acima ou à es- querda dele, que indicam um raciocínio de identidade e não de analogia. Este comportamento também foi observado no teste das Matrizes Progressivas Coloridas de Raven, como um comportamento comum em crianças, conforme está descrito no Manual do teste (Angelini \& cols., 1999).

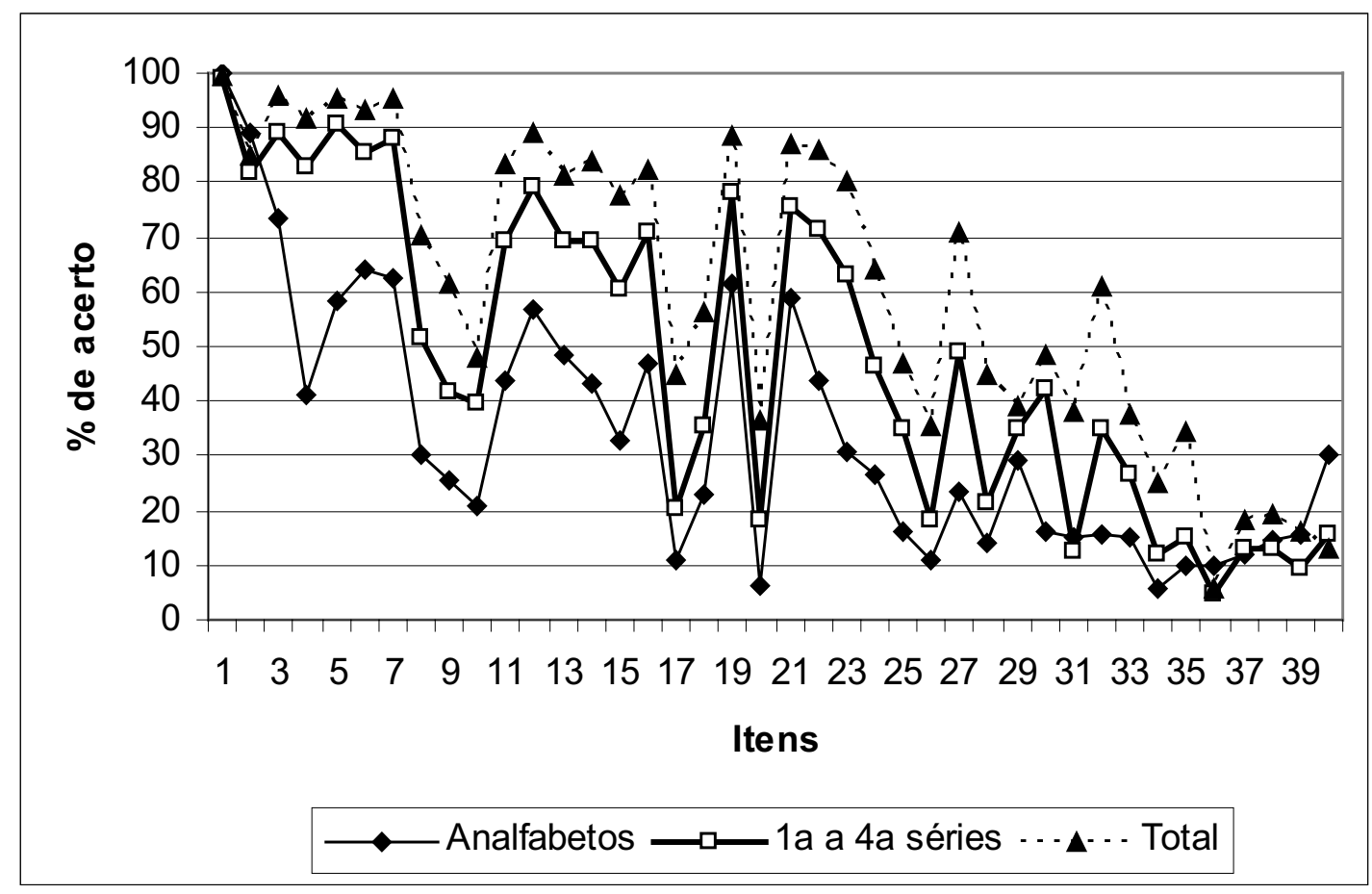

Figura 1. Porcentagens de acerto dos itens desta pesquisa comparadas às de $1^{\mathrm{a}}$ a $4^{\mathrm{a}}$ séries e da amostra total de 1992, do Manual do R-1. 
Pode-se observar que a curva relativa às porcentagens de acertos dos itens dos analfabetos acompanhou a variação das outras amostras, demonstrando uma grande semelhança entre as curvas dos três grupos da Figura 1. Isto mostra que, em geral, a dificuldade relativa dos itens se mantém nos diversos níveis de escolaridade, sendo que os analfabetos têm sempre frequências de acertos menores, exceto nos itens 31 e 36 a 40, em que apresentaram uma melhora na frequência de acertos, sugerindo que a resposta correta é mais atrativa visualmente e que estes itens podem necessitar de revisão. As frequências de acertos caíram à medida que aumentou a dificuldade dos itens e foram bem menores do que as obtidas pela amostra do manual, em que a escolaridade vai da $1^{\mathrm{a}}$ série ao $2^{\mathrm{o}}$ grau.

Comparando as frequências desta pesquisa com as da amostra total de São Paulo do manual do R-1 (Alves, 2002), conforme pode ser observado na Figura 2 , percebe-se que na presente pesquisa houve menos omissões, apesar do maior número de erros em todos os itens, sugerindo que, mesmo não sabendo a resposta, os sujeitos "chutaram mais". Também pode estar associado ao tempo livre para fazer o teste, o que diminuiu a desistência para responder aos itens.

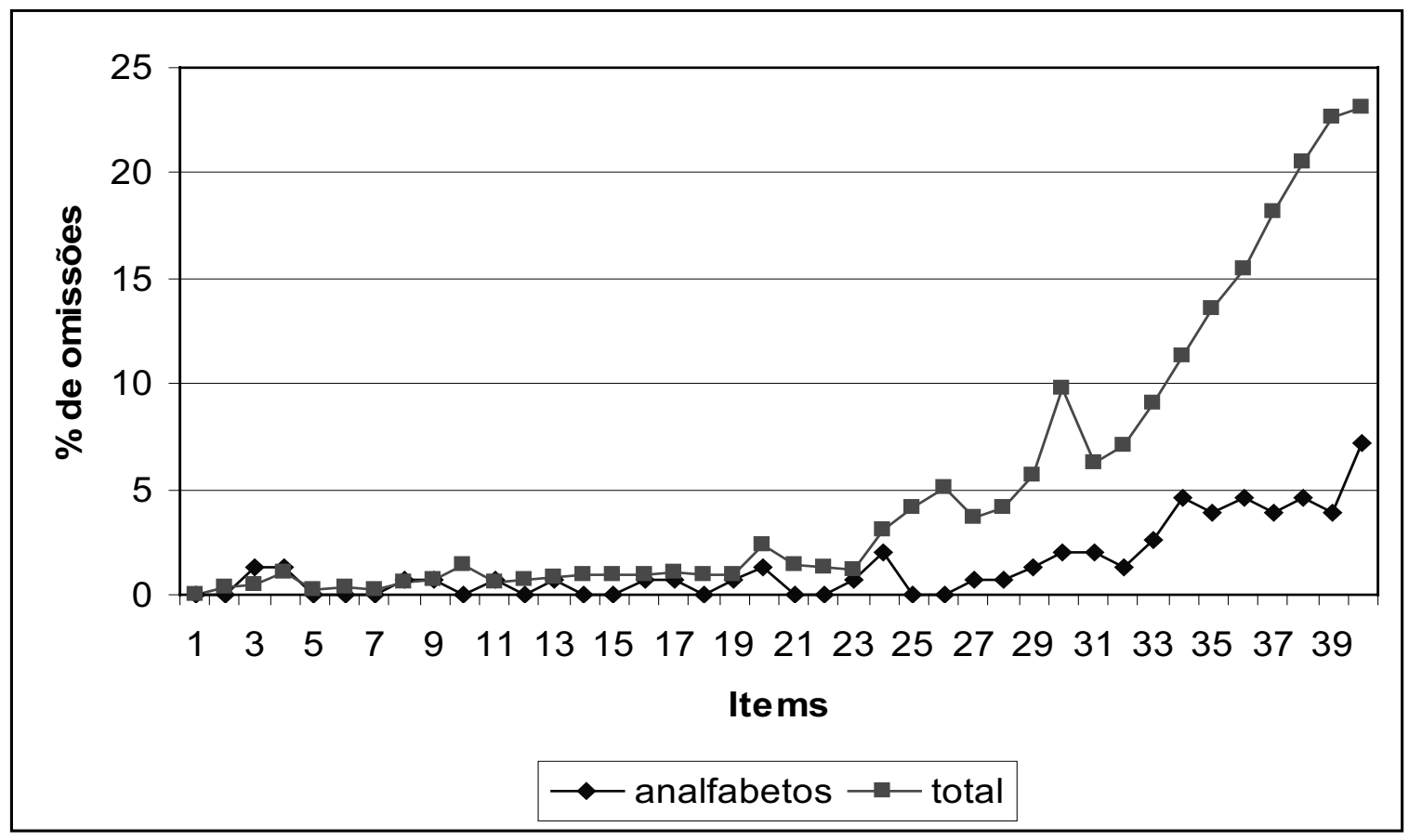

Figura 2. Porcentagens de omissões dos itens desta pesquisa comparadas às de $1^{\mathrm{a}}$ a $4^{\mathrm{a}}$ séries e da amostra total de 1992, do Manual do R-1.

Verificou-se que o número de omissões da amostra de adultos em alfabetização é menor e a diferença cresce a partir do item 23 , praticamente dobrando em relação à amostra de $1^{\mathrm{a}}$ a $4^{\mathrm{a}}$ série. Essa diferença pode ser devida ao fato de que nesta pesquisa não foi considerado o limite de tempo, o que permitiu aos sujeitos responderem o teste até o final, o que não ocorreu nas amostras do Manual.

Para determinar a diferença entre os participantes mais novos e mais velhos foi calculado o teste $t$ entre as médias de pontos, sendo a diferença significante $(\mathrm{t}=4,705, \mathrm{p}<0,001)$. O grupo com idades até 40 anos teve média de 15,31 , e no grupo de 41 anos ou mais, a média decresceu para 11,34. Estes resultados indicam forte influência da idade no desempenho cognitivo dos adultos não alfabetizados.

A Tabela 4 apresenta os percentis do R-1 para adultos analfabetos por sexo, faixas etárias e para a amostra total. 
TABELA 4

Percentis por Sexo, Faixas Etárias e Amostra Total

\begin{tabular}{ccccccc}
\hline Classificação & Percentis & Fem. & Masc. & Até 40 & 41 ou + & Total \\
\hline \multirow{2}{*}{ Inferior } & 1 & 1,0 & 0,0 & 4,0 & 0,0 & 0,5 \\
& 5 & 5,0 & 6,0 & 6,0 & 4,0 & 5,0 \\
\hline \multirow{3}{*}{ Médio Inferior } & 10 & 5,0 & 6,0 & 6,8 & 5,0 & 6,0 \\
& 20 & 7,0 & 8,6 & 9,0 & 6,0 & 7,0 \\
& 25 & 8,0 & 9,0 & 10,0 & 7,0 & 9,0 \\
\hline \multirow{2}{*}{ Médio } & 30 & 9,0 & 9,2 & 11,0 & 8,2 & 9,0 \\
& 40 & 10,0 & 13,0 & 14,0 & 9,0 & 11,0 \\
& 50 & 12,0 & 15,0 & 15,0 & 11,0 & 13,0 \\
& 60 & 13,0 & 17,0 & 17,8 & 12,0 & 15,0 \\
Médio Superior & 70 & 15,0 & 19,0 & 19,0 & 13,0 & 17,0 \\
\hline Superior & 75 & 16,0 & 20,0 & 20,0 & 14,5 & 18,0 \\
\hline Muito Superior & 80 & 18,0 & 21,0 & 21,0 & 16,0 & 19,0 \\
\hline & 90 & 20,0 & 23,6 & 23,2 & 19,0 & 22,0 \\
\hline
\end{tabular}

O total de pontos referente ao percentil 50 desta amostra corresponde ao percentil 25 para cada sexo da amostra de $1^{\mathrm{a}}$ a $4^{\mathrm{a}}$ série de São Paulo de 1992 (Alves, 2002) e ao percentil 20 para a amostra total, o que confirma a inadequação de usar normas obtidas em sujeitos com maior escolaridade.

Segundo Angelini e cols. (1999), há uma tendência de acreditar que a inteligência diminui com o aumento da idade, mas estudos recentes comprovam que os resultados em testes de inteligência demonstram que existe progressão nos resultados independente da idade e afirmam que, se a inteligência fosse mensurada em relação ao tipo de atividade valorizada pela pessoa, provavelmente se provaria que a capacidade aumenta durante toda a vida. Alves (2002) comenta que a inteligência do adulto aumenta até os 50 anos e apresenta um pequeno declínio após essa idade. Assim os resultados mais baixos das pessoas mais idosas são devido à influência de variáveis culturais e nutricionais. Em vista disso é possível supor que o baixo resultado apresentado pelos indivíduos mais velhos dessa amostra esteja relacionado com as vivências pessoais de cada um, principalmente considerando o avanço das tecnologias nos últimos anos, que provavelmente influenciaram de algum modo mais os jovens do que os mais velhos.

\section{CONCLUSÕES}

Os adultos não alfabetizados obtiveram resultados mais baixos no R-1, quando comparados a sujeitos com mais escolaridade, indicando a influência da baixa ou nenhuma escolaridade neste tipo de atividade e de raciocínio, reforçando a ideia da importância do ambiente no desenvolvimento cognitivo. Embora o fator $g$ não esteja associado ao aprendizado acadêmico, a realização do teste implica em hábitos escolares não exercitados neste grupo, como ficar sentado e concentrado em figuras geométricas e abstratas ou buscar relações entre diferentes elementos e sua sequência. Também é possível supor que as diferenças observadas por Castro-Caldas (1998) na organização funcional do cérebro relativas à aprendizagem da leitura possam exercer influência nos resultados dos testes de inteligência.

Alves (2002) comenta que para interpretar o resultado de um teste de inteligência devem ser considerados os anos de escolaridade do sujeito. Por outro lado, os mais velhos foram menos bem sucedidos comparativamente aos mais jovens, o que indica que o aumento da idade também interfere negativamente no desempenho. Esta conclusão remete à necessidade de estudos mais específicos para conhecer a influência da história de cada um, quais as suas experiências escolares, se elas ocorreram, quando iniciaram a escolarização, quanto tempo frequentaram a escola, o motivo da desistência ou se não tiveram nenhuma escolarização. Raven, Raven e Court (1991, citados por Alves, 2002) concluíram que variáveis nutricionais e culturais afetam os resultados, mas estes estudos necessitam de pesquisas longitudinais e mais amplas.

Estes dados mostram que o uso de testes nesta população requer cautela e estudos mais minuciosos, 
desde o desenvolvimento de testes mais adaptados à sua realidade e, sobretudo, um uso mais cuidadoso, com aplicações individuais e utilização de entrevistas para compreender melhor o desempenho, incluindo a indagação sobre os acertos e os erros.

\section{REFERÊNCIAS}

Almeida, L. S. (2002). As aptidões na definição e avaliação da inteligência: O concurso da análise fatorial. Paidéia, 12(23), 517.

Alves, I. C. B. (2002). R-1: Teste Não Verbal de Inteligência Manual. São Paulo: Vetor.

Alves, I. C. B., Colosio, R., \& Ruivo, R. J. (1992). O Teste R-1: Um estudo das variáveis idade, sexo e escolaridade [Resumo]. Em Sociedade Brasileira para o Progresso da Ciência (Org.), Anais da $44^{a}$ Reunião Anual da Sociedade Brasileira para o Progresso da Ciência (p. 904). São Paulo: SBP.

Alves, I. C. B., Colosio, R., \& Ruivo, R. J. (1995). O Teste R-1: Precisão através do reteste. Boletim de Psicologia, 65, 31-36.

Angelini, A. L., Alves, I. C. B., Custódio, E. M., Duarte, W. F., \& Duarte, J. L. M. (1999). Manual - Matrizes Progressivas Coloridas de Raven Escala Especial. São Paulo: Centro Editor de Testes e Pesquisas em Psicologia.

Castilho, A. V. (1985). Análise de novas perspectivas para o estudo da inteligência humana. As medidas de raciocínio analógico e sua inserção no panorama atual da pesquisa. Tese de Doutorado não-publicada, Universidade de São Paulo.

Castro-Caldas, A., Miranda, P. C., Carmo, I., Reis, A., Leote, F., Ribeiro, C., \& Ducla-Soares, E. (1999). Influence of learning to read and write on the morphology of the corpus callosum. European Journal of Neuroscience, 6(1), 23-28.

Castro-Caldas, A., Petersson, K. M., Reis, A., Stone-Elander, S., \& Ingvar, M. (1998). The illiterate brain learning to read and write during childhood influences the functional organization of the adult brain. Brain, 121, 1053-1063.

Ceci, S. J., \& Williams, W. M. (1997). Schooling, intelligence and income. American Psychologist, 52, 1051-1058.
Cronbach, L. J. (1996). Fundamentos da testagem psicológica (C. A. Silveira. Neto, \& M. A. V. Veronese, Trad.). Porto Alegre: Artes Médicas.

Flores-Mendoza, C. (2000). Diferenças intelectuais entre homens e mulheres: Uma breve revisão da literatura. Psicólogo InFormação, 4(4), 25-34.

Rádio das Nações Unidas. (2004). Dia Internacional da Alfabetização - 08 de setembro de 2004. Retirado em 21 de maio de 2005, de http://www.nossosaopaulo.com.br/Reg_SP/Barra_Escolha/ONU_Alfabetizacao.htm

Oliveira, M. K. (2004). Ciclos de vida: Algumas questões sobre a psicologia do adulto. Educação e Pesquisa, 30(2), 211-229.

Oliveira, R. (1973). R-1: Teste Não Verbal de Inteligência - Manual. São Paulo: Vetor.

Petersson, K. M., Silva, C., Castro-Caldas, A., Ingvar, M., \& Reis, A. (2007). Literacy: A cultural influence on functional leftright differences in the inferior parietal cortex. European Journal of Neuroscience, 26(3), 791-799.

Rádio das Nações Unidas. (2004). Dia Internacional da Alfabetização - 08 de setembro de 2004. Retirado em 21 de maio de 2005, de http://www.nossosaopaulo.com.br/Reg_SP/Barra_Escolha/ONU_Alfabetizacao.htm

Roazzi, A., \& Souza, B. C. (2002). Repensando a inteligência. Paidéia, 12(23), 31-35.

Sisto, F. F., Ferreira, A., \& Matos, M. P. B. (2006). TCR e R-1: Duas medidas do fator g. Psic: Revista de Psicologia da Vetor Editora, 7(1), 69-77.

Spearman, C. (1955). Las habilidades del hombre su natureza y medición. (E. Loedel, Trad.). Buenos Aires: Paidós.

Weil, P., \& Nick, E. (1971). O potencial da inteligência do brasileiro: Levantamento e resultados no teste INV - Manual. Rio de Janeiro: Centro Editor de Psicologia Aplicada.

Recebido: 19/12/2007

Última revisão: 02/05/2009 Aceite final: 04/05/2009

\section{Sobre as autoras:}

Maria Olinda Gottsfritz: Psicóloga, Doutora em Psicologia Escolar e do Desenvolvimento Humano pela Universidade de São Paulo, professora da Universidade Presbiteriana Mackenzie.

Irai Cristina Boccato Alves: Psicóloga, Doutora em Psicologia Escolar e do Desenvolvimento Humano pela Universidade de São Paulo, professora da Universidade de São Paulo.

Endereço para correspondência: R. Sócrates, 409 - ap. 34 - Vila Sofia - 04671-071 São Paulo/SP - Endereço eletrônico: magot1@terra.com.br; iraicba@usp.br 